\title{
COVID-19 y retos en la educación médica
}

\section{COVID-19 and challenges in medical education}

\author{
Marco Antonio Chávez Ramírez
}

Citar como: Chávez RMA. COVID-19 y retos en la educación médica. An Med ABC. 2021; 66 (3): 160-161. https://dx.doi. org/10.35366/101661

El mundo seguía su inercia a la velocidad que siempre lo ha hecho, cada país, cada pueblo, cada persona realizaba sus actividades y su vida con la normalidad acostumbrada, mostrábamos nuestros afectos de la manera cercana de acuerdo con los usos y costumbres de cada región, nunca pensamos que un tsunami viral llamado COVID-19 modificaría de forma súbita e impresionante todas las actividades alrededor del planeta y empezaríamos a vivir de forma diferente manifestado por temor, miedo y hasta pánico al ver cómo esta pandemia se apoderaba de miles de vidas por día en todo el planeta.

Ante esta catástrofe sanitaria, una de las profesiones que afrontó de inmediato la enfermedad, que trabajó día y noche (frecuentemente sin descanso) y sacrificando a su familia fuimos los médicos. Algunas especialidades como anestesiología, medicina crítica, neumología, infectología y otros profesionales de la salud se enfrentaron en la primera línea de batalla contra este inesperado virus; como consecuencia, los mecanismos de educación médica han sufrido transformaciones con el fin de mantener ante todo el más alto nivel académico bajo la mística que «en primer lugar están nuestros pacientes».

La educación y/o enseñanza que por definición es la transmisión de conocimientos a una persona para

\footnotetext{
* Anestesiólogo. Jefe Corporativo del Departamento de Anestesiología, Centro Médico ABC. México.
}

Correspondencia:

Marco Antonio Chávez Ramírez

E-mail: jefanes_obs@abchospital.com / drcarm@ hotmail.com que ésta adquiera una determinada formación, en medicina y específicamente en anestesiología cada día se enfrenta a retos más complejos, siendo el más relevante la forma de enseñar y aprender frente al SARS-CoV-2, principalmente por la suspensión de actividades presenciales de forma obligatoria, rotaciones, visitas preoperatorias a distancia, aislamiento tanto físico como psicológico, modificaciones de los establecimientos de salud y muchas otras más de la vida profesional y personal de los médicos, que nos obligaron a plantear nuevos métodos y técnicas con el fin de cumplir con los programas establecidos y mantener la alta calidad en la educación de nuestra especialidad; sin embargo, a pesar de todos los esfuerzos realizados por la humanidad y algunas organizaciones médicas, muchos países se vieron obligados a cancelar especialidades en virtud de que más del $80 \%$ de la ocupación hospitalaria eran pacientes SARS-CoV-2 y existía gran riesgo de contraer la enfermedad. ${ }^{1,2}$

Especialidades como la nuestra requieren, además de la esfera cognitiva, desarrollar una serie de destrezas psicomotoras y de precisión que solamente se adquieren durante los procedimientos anestésicos, los cuales eran mínimos, por lo que nos vimos obligados a utilizar métodos alternativos como es el uso de simuladores, que afortunadamente tenemos en nuestra institución, un área equipada de muy alto nivel, así como realizar videoconferencias, clases y presentaciones de casos clínicos virtuales. ${ }^{3}$

Los cambios siempre son buenos para bien o para mal, en el rubro de la educación médica avanzamos y aprendimos gracias a la pandemia en un año, lo que probablemente nos tardaríamos muchos más, tanto que actualmente se realizan reuniones, cursos, 
congresos, alrededor del mundo en los que podemos tener presencia virtual y hasta realizar comentarios desde la comodidad de nuestras casas.

Podríamos seguir comentando tantas situaciones, experiencias y vivencias afrontadas durante esta interminable enfermedad que nos obligó a cambiar, pero nunca será igual por más que hayamos avanzado utilizando la tecnología, el hecho de realizar nuestras actividades de educación estando reunidos, viéndonos de frente, discutiendo, comentando, opinando los casos clínicos así como las clases presenciales y hasta tutelares en donde podemos mostrar nuestros sentimientos de manera directa ante nuestros médicos residentes, quienes son el motor académico de una institución, por tal motivo siempre he expresado que «un hospital sin enseñanza no es hospital».
Para finalizar debo decir que hasta el día de hoy el reto más importante sigue siendo mantener la alta calidad en la educación médica superando las adversidades existentes consecutivas al tsunami SARS-CoV-2.

\section{REFERENCIAS}

1. Alemán I, Vera E, Patiño-Torres MJ. COVID-19 y la educación médica: retos y oportunidades en Venezuela. Educ Med. 2020; 21 (4): 272-276.

2. England AJ, Jenkins BJ. Time spent in the clinical environment is the most important aspect of medical education - we need to protect it. Anaesthesia. 2017; 72 (11): 1306-1311.

3. Ruiz Speare JO, Valdés SF, Velázquez HB. El ABC de la educación médica por simuladores. México: Editorial Alfil; 2020. 